\title{
Bis-cyclooctatetraenyl Thulium(II): Highly Reducing Lanthanide Sandwich Single Molecule Magnets
}

Jules Moutet, ${ }^{1}$ Jules Schleinitz, ${ }^{1}$ Leo La Droitte, ${ }^{2}$ Maxime Tricoire, ${ }^{1}$ Frédéric Gendron, ${ }^{2}$ Thomas Simler, ${ }^{1}$ Carine Clavaguéra, ${ }^{3}$ Boris Le Guennic, ${ }^{2}$ Olivier Cador $^{2}$ and Grégory Nocton*1

1. LCM, CNRS, Ecole polytechnique, Institut Polytechnique Paris, Route de Saclay, 91128 Palaiseau, cedex, France E-mail: gregory.nocton@polytechnique.edu

2. Institut des Sciences Chimiques de Rennes, UMR 6226 CNRS, Université de Rennes 1, 263 avenue du Général Leclerc, 35042 Rennes cedex, France

3. Institut de Chimie Physique, UMR 8000, CNRS, Université Paris-Saclay, 15 avenue Jean Perrin, 91405 Orsay cedex, France

In memory of Prof. R. A. Andersen - a great mentor and friend

\begin{abstract}
Divalent lanthanide organometallics are well known highly reducing compounds usually used for single electron transfer reactivity and small molecule activation. Thus, their very reactive nature prevented for many years the study of their physical properties, such as magnetic studies on a reliable basis. In this article, the access to rare organometallic sandwich compounds of TmII with the cyclooctatetraenyl (Cot) ligand impacts on the use of divalent organolanthanide compounds as an additional strategy for the design of performing Single Molecule Magnets (SMM). Herein, the first divalent thulium sandwich complex with $\mathrm{f}^{13}$ configuration behaving as a Single Molecule Magnet in absence of DC field is highlighted.
\end{abstract}


In recent years, organolanthanide chemistry has been revitalized by the discovery of high blocking temperature lanthanide-based Single Molecule Magnets bearing typical organometallic ligands, such as the cyclopentadienyl $(\mathrm{Cp})^{[1]}$ and the cyclooctatetraenyl (Cot) ligand. ${ }^{[2]}$ These ligands are indeed well adapted to access original and useful geometries that are more difficult to obtain with other coordination compounds. ${ }^{[1 b]}$ The use of a larger aromatic ligand, the cyclononatretraenyl (Cnt) ligand, recently led to the formation of perfectly linear neutral complexes of divalent lanthanides $(\operatorname{Ln}(\mathrm{II}))^{[3]}$ and to heteroleptic complexes bearing both the Cot and Cnt ligands. ${ }^{[4]}$ The synthetic description and structural analyses of such compounds remain very challenging in organometallic chemistry but the principal purpose of their reports has moved in the last years from reactivity, $\operatorname{redox}^{[5]}$ or polymerization studies to attractive magnetic properties. As such, organolanthanide complexes with spectacular magnetic properties were until very recently ${ }^{[6]}$ reserved for trivalent lanthanides but not divalent ones.

Yet, divalent lanthanide complexes have great advantages because they are powerful singleelectron sources, ${ }^{[5]}$ and have been used in reductive organic chemistry ${ }^{[7]}$ and for small molecule activation. ${ }^{[8]}$ The study of their electronic structures is also an important fundamental topic since the configuration of $\mathrm{Ln}^{\mathrm{II}}$ ions is either $4 \mathrm{f}^{\mathrm{n}},{ }^{[9]}$ or $4 \mathrm{f}^{\mathrm{n}-1} 5 \mathrm{~d}^{1}$ if the empty $5 \mathrm{~d}$ orbitals are close enough to become populated. ${ }^{[6,10]}$ Additionally, if ligand orbitals are involved in this picture, energy states with intermediate valence emerge. ${ }^{[11]}$

Divalent lanthanide organometallic complexes containing the Cot ligand are underexplored for their magnetic properties because of their intricate syntheses ${ }^{[12]}$ and their highly reducing power. For example, reactions of divalent lanthanide halide sources with aromatic molecules such as cyclooctatetraene led to trivalent thulium Cot compounds, ${ }^{[13]}$ some of which behave as field-induced SMMs. ${ }^{[2 c]}$ Despite these difficulties, well-defined divalent lanthanide organometallics with inverted and multiple decker sandwiches of Cot ligand have been reported. ${ }^{[14]}$ In comparison with bulky substituted Cp ligands, ${ }^{[1 b-d, ~ 1 f, ~ 6] ~ t h e ~ a c c e s s ~ t o ~ h i g h l y ~}$ symmetrical Cot- and Cnt-based compounds from a symmetry-adapted argument ${ }^{[3,15]}$ should simplify the bonding description.

We have been studying complexes containing divalent thulium ${ }^{[9,16]}$ for several years for the principal reason that $\mathrm{Tm}^{\mathrm{II}}$ is very reactive and useful in single-electron transfer reaction but also because it is isoelectronic to $\mathrm{Yb}^{\mathrm{III}}{ }^{[9]}$, with a $4 \mathrm{f}^{13}$ configuration. The resulting one-hole electronic structure may simplify the spectroscopic features as a first approximation. Recently, some of us reported the first divalent lanthanide coordination complex exhibiting a slow magnetic relaxation under a weak DC field. ${ }^{[16 c]}$ The need for this small DC field is typical in $\mathrm{f}^{13}$ compounds. ${ }^{[17]}$ In this article, we extend this concept to the use of large typical organometallic ligands with rare occurrences in the divalent state. We report a highly 
reducing divalent thulium sandwich complex behaving as a Single Molecule Magnet in zero DC field.

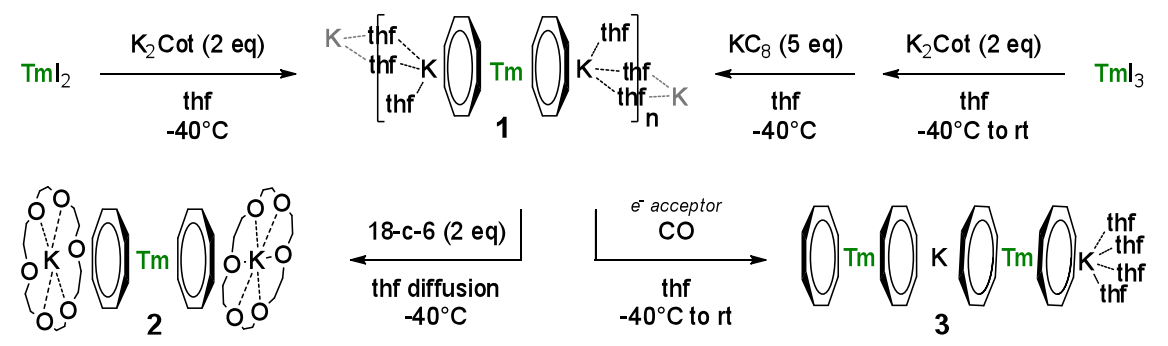

Scheme 1. Synthetic scheme for the preparation of 1,2 and 3.

The bis-cyclooctatetraenyl sandwich complex $(\mathrm{Cot})_{2} \mathrm{TmK}_{2}(\text { thf })_{4}$, 1, was prepared in good yield by salt metathesis from thulium bis-iodide and freshly prepared $\mathrm{K}_{2} \mathrm{Cot}$ at low temperature $\left(-40^{\circ} \mathrm{C}\right)$ in thf (scheme 1). This procedure is similar to that used for the synthesis of $\mathrm{Tm}(\mathrm{OTf})_{2}{ }^{\left[{ }^{[9]}\right.}$ After filtration of the KI formed during the reaction, the concentrated deep green solution is kept cold to yield large X-ray suitable dark green blocks of $\mathbf{1}$. Alternatively, 1 can be synthesized in better yield by reduction with $\mathrm{KC}_{8}$ of the trivalent $(\mathrm{Cot})_{2} \mathrm{TmK}$ complex made in situ from $\mathrm{TmI}_{3}$ and freshly prepared $\mathrm{K}_{2}$ Cot. 1 is well soluble in thf and addition of 18-crown-6 (18-c-6) to tentatively trap the potassium cations led to dark green insoluble material. Thus, a solution of 18-c-6 in cold thf was slowly diffused into a cold solution of 1 and X-ray suitable green crystals of $(\operatorname{Cot})_{2} \operatorname{Tm}\{\mathrm{K}(18-\mathrm{c}-6)\}_{2}, 2$, appeared at the interface in good yield.

One broad signal at $-5.23 \mathrm{ppm}$ appears in the room temperature (293 K) ${ }^{1} \mathrm{H}$ NMR spectrum of 1 (Figure S1) in thf- $d_{8}$. A relative small shift of the chemical shift compared to diamagnetic analogues is typical of divalent Tm complexes in opposition to highly paramagnetic trivalent Tm complexes. ${ }^{[18]}$ Variable temperature ${ }^{1} \mathrm{H}$ NMR studies (Figure S2) only reveal a broadening of the signal upon decreasing the temperature and show a linear plot for $\delta v s 1 / T$, which is indicative of a Curie behavior of the magnetic susceptibility in the $223-363 \mathrm{~K}$ temperature regime. Complex 2 is not soluble in thf- $d_{8}$ or in any of the hydrocarbon solvents commonly used for this sensitive chemistry and no NMR spectrum could be obtained.

Complex 1 crystalizes in $P$-1 while 2 in the monoclinic $P 2_{1} / n$ space group (Figure 1). Both 1 and $\mathbf{2}$ are sandwich complexes made of Cot ligands located above and below the thulium ion. The C-C distances in Cot are ranging from 1.384(17) to 1.445(17) $\AA$ in $\mathbf{1}$ and from 1.387(7) to $1.420(7) \AA$ in 2 , indicative of a delocalized aromatic $\mathrm{p}$ system. The Tm-C distance is 2.74(2) $\AA$ in average, ranging from 2.703(14) to 2.764(14) $\AA$, and 2.73(3) $\AA$ in average, ranging from 2.679(5) to 2.772(4) $\AA$, in $\mathbf{1}$ and 2, respectively, while the average $\mathrm{Tm}-\mathrm{Ctr}$ (Ctr is for centroid) distances are identical in both $\mathbf{1}$ and $\mathbf{2}$ (2.02(2) $\AA$ ) (Table S1). These distances 
are significantly longer than the $\mathrm{Tm}^{\mathrm{III}}$-Ctr distances reported in the literature ranging from $1.7017(3) \AA$ to $1.861 \AA{ }^{[2 c, 13,19]}$ to one exception corresponding to a triple decker arrangement reported by Edelmann, in which the Cot ligand is sandwiched between two trivalent $\mathrm{Tm}$ $\left(\mathrm{Tm}^{\mathrm{III}}-\mathrm{Ctr}\right.$ distance of $\left.2.043 \AA\right) .{ }^{[19 \mathrm{f}]}$ The relatively long Tm-Ctr distances are therefore indicative of the divalent nature of the thulium center in $\mathbf{1}$ and $\mathbf{2}$.

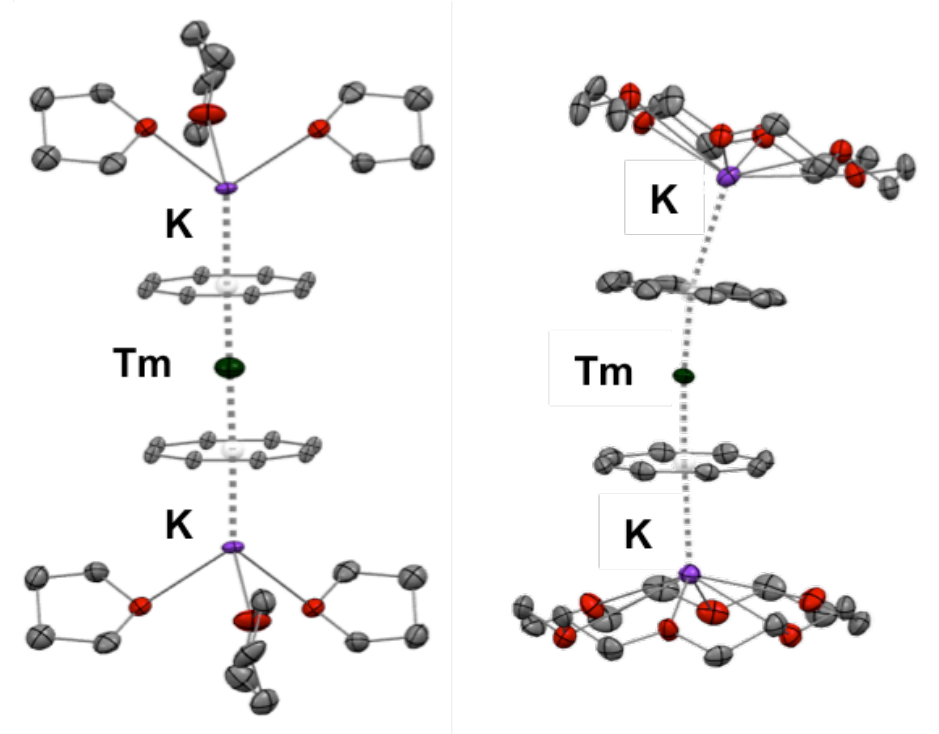

Figure 1. ORTEP of 1 and 2. Hydrogen atoms and Cot carbon disorder have been removed for clarity.

Comparatively, the divalent ytterbium half sandwich $(\mathrm{Cot}) \mathrm{Yb}\left(\mathrm{C}_{5} \mathrm{H}_{4} \mathrm{~N}\right)_{3}$ has $\mathrm{Yb}-\mathrm{Ctr}$ distances between 1.91 and $1.92 \AA{ }^{[12]}$ while the isomorphous complex of $\mathrm{Eu}^{\mathrm{II}}$ has a distance of 2.153 $\AA{ }^{[14 \mathrm{c}]}$ in agreement with a smaller ionic radius for Tm compared to Eu. ${ }^{[20]}$ In 1, each potassium is coordinated with three molecules of thf, two of them bridging between two potassium ions, resulting in a zig-zag polymeric chain (Figure S10), while the 18-c-6 coordination of the potassium prevents the formation of a polymer in 2 . $T$ he $\operatorname{Ctr}(\operatorname{Cot})-\mathrm{K}$ average distance is 2.37(2) $\AA$ in $\mathbf{1}$ and 2.69(10) $\AA$ 2. The significant difference is due to the coordination of the six oxygen donor atoms reducing the interaction of the potassium ion with the Cot ligand. Finally, the Cot-Tm-Cot angle of $173.9^{\circ}$ is more bent in 2 compared to that nearly linear of $179.8^{\circ}$ in $\mathbf{1}$. The K-Tm-K angle bends from $180.0^{\circ}$ to $164.5^{\circ}$ in $\mathbf{1}$ and $\mathbf{2}$, respectively (Figure 1).

Both complexes $\mathbf{1}$ and $\mathbf{2}$ are extremely sensitive to air, moisture and temperature, especially $\mathbf{2}$. It is plausible that the polymeric nature of $\mathbf{1}$ makes it more stable, comparatively. Reactions with typical reactants used in divalent lanthanide chemistry, such as pyridine, ${ }^{[21]}$ bipyridine, or carbon monoxide, and with transition metal precursors used in the formation of heterobimetallic complexes ${ }^{[11 \mathrm{~b}, 22]}$ were performed but all these led to one same product, the tetra-decker $\left[(\mathrm{Cot})_{2} \mathrm{Tm}\right]_{2}(\mathrm{~m}-\mathrm{K})\left(\mathrm{K}(\mathrm{thf})_{4}\right), \mathbf{3}$, that was crystalized very easily from all reaction 
mixtures. The formation of this trivalent compound, which is isomorphous of the known $\left[(\mathrm{Cot})_{2} \mathrm{Ln}\right]_{2}(\mu-\mathrm{K})\left(\mathrm{K}(\mathrm{thf})_{4}\right) \mathrm{Ln}=\mathrm{Er}, \mathrm{Gd},{ }^{[23]}$ is indicative of a fast electron transfer and not likely a coordination induced electron transfer. An ORTEP of $\mathbf{3}$ and crystal structure description are found in SI.

The useful qualitative static model reported by Rinehart and Long predicts that $\mathrm{f}^{13}$ elements have a prolate shape ${ }^{[24]}$ of the electron density and therefore require equatorial coordination to stabilize Ising ground states. The ground state multiplet ${ }^{2} \mathrm{~F}_{7 / 2}$ splits in four terms. A close analysis of the electrostatic model shows that a sandwich geometry with large $\mathrm{p}$ aromatic ligands best leads to $\mathrm{m}_{J}= \pm 5 / 2$ rather than the $\mathrm{m}_{J}= \pm 7 / 2$ obtained with a strong equatorial ligand field.

Ab-initio theoretical calculations were performed at the CASSCF and CASPT2 level (see computational methods). All methods confirmed the pure $\mathrm{m}_{J}= \pm 5 / 2$ ground state for both $\mathbf{1}$ and 2 (See Table S9-S18), followed by the $\mathrm{m}_{J}= \pm 3 / 2$, the $\mathrm{m}_{J}= \pm 7 / 2$ and the $\mathrm{m}_{J}= \pm 1 / 2$ but the energy gaps between the excited states differ slightly depending upon the method used. The presence of the potassium and of the thf and 18-crown-6 molecules in the computation do not influence the ground-state composition and only marginally the energy splitting of the crystal field states. Thus, from the computations, 1 and $\mathbf{2}$ possess similar ground states, and similar magnetic properties were anticipated.

The variable temperature magnetic data were recorded both in DC and in AC. Figure 2 shows the DC magnetic data recorded for 1 and 2 over the 2-300 K temperature range. The $\mathrm{M}$ vs $\mathrm{H}$ curves at $2 \mathrm{~K}$ follow a similar trend with a higher value for $\mathbf{2}$ than for $\mathbf{1}$ at low temperature, $\left(\chi_{\mathrm{M}} \mathrm{T}\right.$ values of $1.11 \mathrm{~cm}^{3} \mathrm{~K} \mathrm{~mol}^{-1}$ for 1 and $1.44 \mathrm{~cm}^{3} \mathrm{~K} \mathrm{~mol}^{-1}$ for 2 ). The difference in ground state between these two compounds was rather difficult to interpret. However, because $\mathbf{2}$ is extremely sensitive to thermal decomposition, it could come from possible decomposition at the drying step. No elemental analysis of $\mathbf{2}$ could be obtained for the same reason. Thus, the AC analysis of $\mathbf{2}$ was performed only on freshly filtered dark green crystals without further drying step under reduced pressure. 


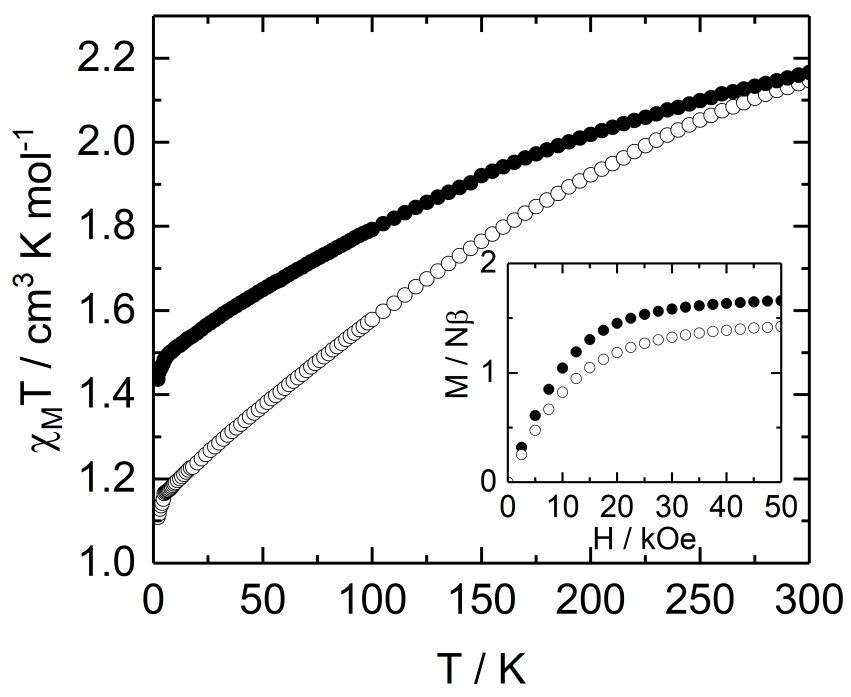

Figure 2. Temperature variations of $\chi_{M} T$ for compounds 1 (empty symbols) and $\mathbf{2}$ (full symbols) with the magnetization curves at $2 \mathrm{~K}$ in inset.

The scan field performed on 2 shows zero-field SMM behavior at $10 \mathrm{kHz}$ (Figure 3). The low frequency limit $(100 \mathrm{~Hz})$ of the AC susceptibility provides $\chi_{\mathrm{M}} \mathrm{T}$ equal to $1.06 \mathrm{~cm}^{3} \mathrm{~K} \mathrm{~mol}^{-1}$, which is in better agreement with that of $\mathbf{1}$ and matches with the calculations (stabilization of $\mathrm{m}_{\mathrm{J}}= \pm 5 / 2$ Kramers doublet ground state). The application of a moderate field completely shifts the maximum to lower frequency, which falls outside the investigation window (Figure S7). There is no maximum in the $\chi_{M}$ "' vs. frequency curve at 0 Oe, which prevents fitting the data with the extended Debye model, but the slow relaxation persists (visible) up to $10 \mathrm{~K}$ (Figure 3). On the other hand, $\mathbf{1}$ does not show any out-of-phase signal in zero external DC field on 2 down to $2 \mathrm{~K}$. The application of an external DC field produces relaxation that grows in amplitude with the external DC field and with a maximum centered around $10 \mathrm{~Hz}$ at $2 \mathrm{~K}$ (Figure S8).

The magnetic curves of $\mathbf{1}$ and $\mathbf{2}$ were compared to the ones obtained from the computations at various levels of theory and confirmed that the $\mathrm{f}^{13}$ configuration imposes the use of methods that include dynamic correlation (CASPT2) to get a reasonable - yet not perfect - agreement with the experiment. The excited states are found at $384 \mathrm{~cm}^{-1}, 438 \mathrm{~cm}^{-1}$ and $744 \mathrm{~cm}^{-1}$ for $\mathbf{1}\left[\mathbf{K}_{2}\right]$ explaining the monotone increase of the magnetic curve over the 2-300 K temperature range. In agreement with an adapted $\mathrm{m}_{J}=5 / 2$ ground state, the magnetization calculated curve agrees very well with the experimental one. A very similar energy splitting was found for $2\left[K_{2}\right]\left(400 \mathrm{~cm}^{-1}, 448 \mathrm{~cm}^{-1}\right.$ and $\left.757 \mathrm{~cm}^{-1}\right)$, confirming that the different magnetic relaxation properties observed in $\mathbf{1}$ and $\mathbf{2}$ (the presence or not of open hysteresis at zero DC field) would be better explained by lattice contribution to the relaxation. 


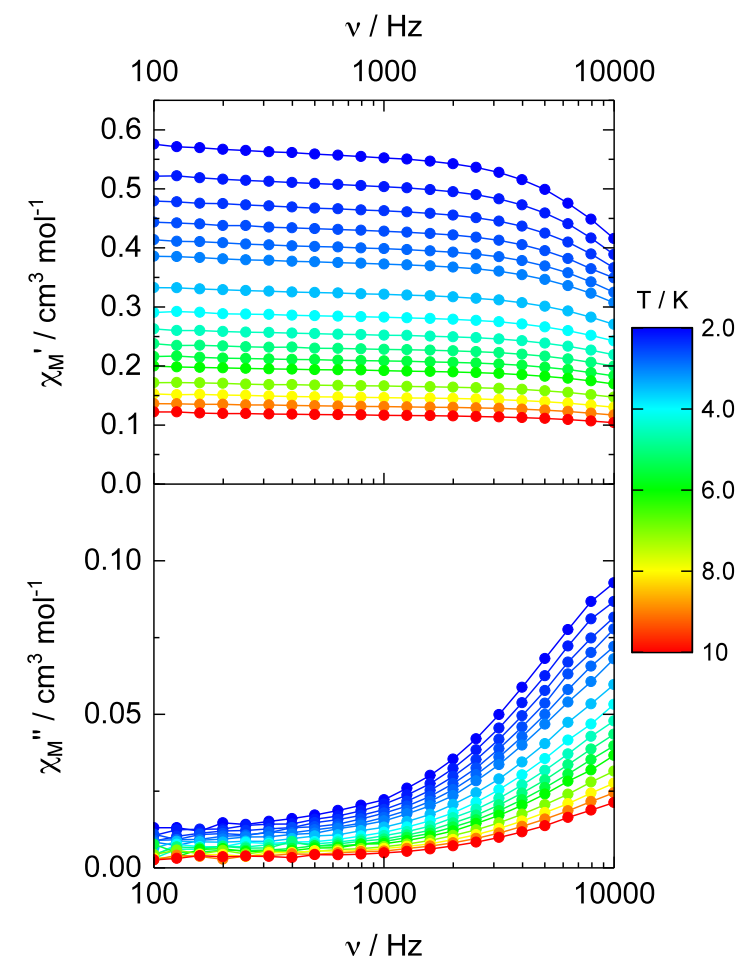

Figure 3. Frequency dependences of both in-phase, $\chi_{M}$ ', and out-of-phase, $\chi_{M}$ ', components of the ac susceptibility for 2 at zero external dc field between 2 and $10 \mathrm{~K}$.

In zero-field, Ln-SMM relaxation is often dominated by quantum tunneling of the magnetization (QTM), ${ }^{[25]}$ and also hyperfine interactions in this particular case because of a single $\mathrm{I}=1 / 2$ isotope for thulium. Dipolar contributions can be easily tested by dilution experiments of the $\mathrm{Tm}^{\mathrm{II}}$ compounds $\mathbf{1}$ and $\mathbf{2}$ into a diamagnetic matrix. In this case, the nearest right neighbor in the periodic table, $\mathrm{Yb}$, which is diamagnetic in its divalent state and presents a comparable ionic radius, is an ideal candidate. The synthesis of a diluted sample of 1 can thus be achieved by the salt metathesis reaction of $\mathrm{K}_{2}$ Cot with a mixture of $\mathrm{YbI}_{2}(90 \%)$ and $\mathrm{TmI}_{2}(10 \%)$. This reaction led to the formation of compound 4 whose X-ray diffraction structure as well as bonding distances are very similar to those in 1. Similarly, substitution of the thf ligands in 4 by 18-c-6 ligands led to 5, the diluted analogue of 2 (Table S1 and Figures $\mathrm{S} 13-\mathrm{S} 14)$. The proportion of $\mathrm{Yb}$ and $\mathrm{Tm}$ could not be determined by XRD since the ratio is too small, but the elemental analysis results indicate a ratio of $\mathrm{Yb}$ :Tm being 98:2.

Dynamic AC susceptibility measurements on the diluted samples of 1 (4) and 2 (5) show outof-phase component that emerges at high frequency, $10 \mathrm{kHz}$ for $\mathbf{4}$, and relative low frequency $3 \mathrm{~Hz}$ for $\mathbf{5}$, in zero external DC field and at $2 \mathrm{~K}$. This slow relaxation process disappears with the application of an external DC field probably at the expense of a growing process at much lower frequency (below $1 \mathrm{~Hz}$ ) for $\mathbf{4}$ and out of the investigation time window for $\mathbf{5}$. For $\mathbf{4}$, the hysteresis loop at $2 \mathrm{~K}$ measured at $16 \mathrm{Oe} \mathrm{s}^{-1}$ reveals magnetic memory effect (slight opening of the loop) at moderate field with a butterfly shape, while for $\mathbf{5}$, the hysteresis loop at $2 \mathrm{~K}$ 
reveals in-field memory effect with a butterfly shape (Figure S9). In zero-field, an out-ofphase signal (maximum) persists up to $30 \mathrm{~K}$ (Figure 4) in $\mathbf{5}$.

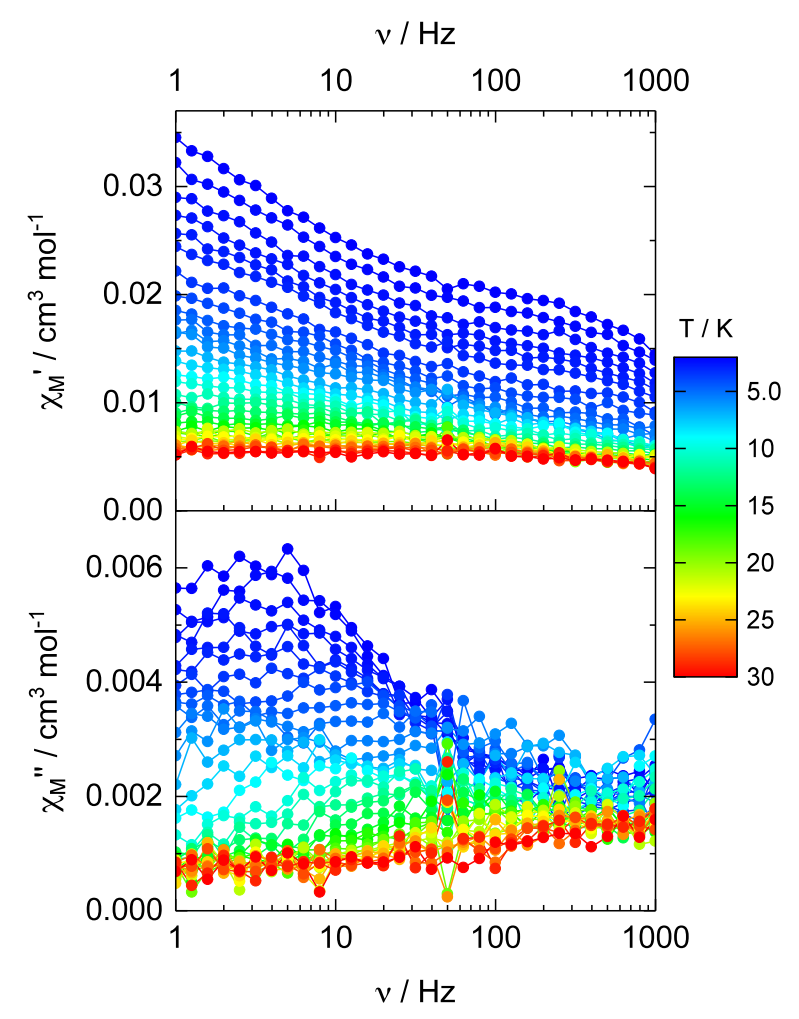

Figure 4. Frequency dependences of both in-phase, $\chi_{\mathrm{M}}$ ', and out-of-phase, $\chi \mathrm{M}^{\mathrm{M}}$ ', components of the ac susceptibility for 5 at zero external dc field between 2 and $30 \mathrm{~K}$.

The calculation of dipolar contributions in both complexes was performed, showing only small contributions and similar ones between 1 and 2 (Table S19-S20), which tends to indicate that small structural modifications drastically influence the magnetic relaxation in organolanthanides. An interesting finding of this work is the relative link between the high reactivity of the divalent compounds with the SMM properties. It would indicate that the reasons for stability of the divalent thulium complex (rigidity of the bulk, kinetic inertness) are somehow related to what enhances slow relaxation properties in these compounds (dipolar, vibronic contributions). This shall serve us as a guide in further divalent organolanthanide complex design.

In conclusion, this work presents the first $\mathrm{f}^{13}$ compound, with only one hole in the f-shell, behaving as a Single Molecule Magnet in absence of DC field. The out-of-phase signal persists up to $10 \mathrm{~K}$ at high frequencies in the condensed phase and up to $30 \mathrm{~K}$ in the diluted phase. The findings of this work contribute to show that the rational geometric design of lanthanide SMM, which is based on a simple electrostatic model, remains perfectly valid and, as other groups showed earlier, ${ }^{[1 b-f, 6]}$ organometallic lanthanide compounds are highly suitable for the design of performing SMMs. However, yet pathways for the magnetic 
relaxation still remain to be investigated because it seems that very small changes cause large consequences on the SMM properties. The reasons for relative stability - or high reactivity of divalent lanthanides may help to dig deeper in this direction.

\section{Acknowledgements}

This work is part of a project that has received funding from the European Research Council (ERC) under the European Union's Horizon 2020 research and innovation program under grant agreement No 716314. Parts of this project have received funding from ANR (French National Research Agency) under project number ANR-19-CE07-0019-1. CNRS and Ecole polytechnique are thanked for funding. F.G. acknowledges the Stratégie d'Attractivité Durable (SAD18006 - LnCPLSMM) and the European Research Council under the European Union's Horizon 2020 research and innovation program (ERC-CoG MULTIPROSMM, Grant agreement No. 725184) for financial supports. F.G and B.L.G thank the French GENCI/IDRIS-CINES center for high performance computing resources.

Keywords: Lanthanides • Organometallics • Single Molecule Magnets • Electron transfer •

Divalent thulium

\section{References}

[1] a) F.-S. Guo, B. M. Day, Y.-C. Chen, M.-L. Tong, A. Mansikkamäki, R. A. Layfield, Angew. Chem. Int. Ed. 2017, 56, 11445-11449; b) B. M. Day, F.-S. Guo, R. A. Layfield, Acc. Chem. Res. 2018, 51, 1880-1889; c) F.-S. Guo, B. M. Day, Y.-C. Chen, M.-L. Tong, A. Mansikkamäki, R. A. Layfield, Science 2018; d) C. A. P. Goodwin, F. Ortu, D. Reta, N. F. Chilton, D. P. Mills, Nature 2017, 548, 439; e) C. A. P. Goodwin, D. Reta, F. Ortu, N. F. Chilton, D. P. Mills, J. Am. Chem. Soc. 2017, 139, 18714-18724; f) K. R. McClain, C. A. Gould, K. Chakarawet, S. Teat, T. J. Groshens, J. R. Long, B. G. Harvey, Chem. Sci. 2019.

[2] a) K. R. Meihaus, J. R. Long, J. Am. Chem. Soc. 2013, 135, 17952-17957; b) J. J. Le Roy, I. Korobkov, M. Murugesu, Chem. Commun. 2014, 50, 1602-1604; c) K. L. M. Harriman, I. Korobkov, M. Murugesu, Organometallics 2017, 36, 4515-4518; d) J. D. Hilgar, M. G. Bernbeck, B. S. Flores, J. D. Rinehart, Chem. Sci. 2018, 9, 7204-7209; e) J. D. Hilgar, M. G. Bernbeck, J. D. Rinehart, J. Am. Chem. Soc. 2019, 141, 1913-1917.

[3] M. Xémard, S. Zimmer, M. Cordier, V. Goudy, L. Ricard, C. Clavaguéra, G. Nocton, J. Am. Chem. Soc. 2018, 140, 14433-14439.

[4] L. Münzfeld, C. Schoo, S. Bestgen, E. Moreno-Pineda, R. Köppe, M. Ruben, P. W. Roesky, Nature Commun. 2019, 10, 3135.

[5] W. J. Evans, Organometallics 2016, 35, 3088-3100.

[6] C. A. Gould, K. R. McClain, J. M. Yu, T. J. Groshens, F. Furche, B. G. Harvey, J. R. Long, J. Am. Chem. Soc. 2019, 141, 12967-12973.

[7] a) M. Szostak, D. J. Procter, Angew. Chem. Int. Ed. 2012, 51, 9238-9256; b) H.-M. Huang, J. J. W. McDouall, D. J. Procter, Nature Catal. 2019, 2, 211-218. 
[8] aM. Xémard, M. Cordier, E. Louyriac, L. Maron, C. Clavaguéra, G. Nocton, Dalton Trans. 2018, 47, 9226-9230; bF. Jaroschik, A. Momin, F. Nief, X. F. Le Goff, G. B. Deacon, P. C. Junk, Angew. Chem. Int. Ed. 2009, 48, 1117-1121; cW. J. Evans, G. Zucchi, J. W. Ziller, J. Am. Chem. Soc. 2003, 125, 10-11.

[9] M. Xémard, A. Jaoul, M. Cordier, F. Molton, O. Cador, B. Le Guennic, C. Duboc, O. Maury, C. Clavaguéra, G. Nocton, Angew. Chem. Int. Ed. 2017, 56, 4266-4271.

[10] M. R. MacDonald, J. E. Bates, M. E. Fieser, J. W. Ziller, F. Furche, W. J. Evans, J. Am. Chem. Soc. 2012, 134, 8420-8423.

[11] a) G. Nocton, W. L. Lukens, C. H. Booth, S. S. Rozenel, S. A. Melding, L. Maron, R. A. Andersen, J. Am. Chem. Soc. 2014, 136, 8626-8641; b) V. Goudy, A. Jaoul, M. Cordier, C. Clavaguéra, G. Nocton, J. Am. Chem. Soc. 2017, 139, 10633-10636; c) R. L. Halbach, G. Nocton, C. H. Booth, L. Maron, R. A. Andersen, Inorganic Chemistry 2018, 57, 7290-7298; d) C. H. Booth, M. D. Walter, D. Kazhdan, Y.-J. Hu, W. W. Lukens, E. D. Bauer, L. Maron, O. Eisenstein, R. A. Andersen, J. Am. Chem. Soc. 2009, 131, 64806491; e) M. D. Walter, C. H. Booth, W. W. Lukens, R. A. Andersen, Organometallics 2009, 28, 698-707; fC. H. Booth, D. Kazhdan, E. L. Werkema, M. D. Walter, W. W. Lukens, E. D. Bauer, Y.-J. Hu, L. Maron, O. Eisenstein, M. Head-Gordon, R. A. Andersen, J. Am. Chem. Soc. 2010, 132, 17537-17549.

[12] A. L. Wayda, I. Mukerji, J. L. Dye, R. D. Rogers, Organometallics 1987, 6, 1328-1332.

[13] I. L. Fedushkin, M. N. Bochkarev, S. Dechert, H. Schumann, Chem. Eur. J. 2001, 7, 3558-3563.

[14] a) U. Reißmann, P. Poremba, L. Lameyer, D. Stalke, F. T. Edelmann, Chem. Commun. 1999, 1865-1866; b) A. Edelmann, S. Blaurock, V. Lorenz, L. Hilfert, F. T. Edelmann, Angew. Chem. Int. Ed. 2007, 46, 6732-6734; c) W. J. Evans, J. L. Shreeve, J. W. Ziller, Polyhedron 1995, 14, 2945-2951; d) W. J. Evans, M. A. Johnston, M. A. Greci, J. W. Ziller, Organometallics 1999, 18, 1460-1464; e) W. J. Evans, R. D. Clark, M. A. Ansari, J. W. Ziller, J. Am. Chem. Soc. 1998, 120, 9555-9563; f) W. J. Evans, M. A. Johnston, R. D. Clark, R. Anwander, J. W. Ziller, Polyhedron 2001, 20, 2483-2490.

[15] A. Kerridge, Dalton Trans. 2013, 42, 16428-16436.

[16] aL. Jacquot, M. Xémard, C. Clavaguéra, G. Nocton, Organometallics 2014, 33, 41004106; bG. Nocton, L. Ricard, Chem. Commun. 2015, 51, 3578-3581; cM. Xémard, M. Cordier, F. Molton, C. Duboc, B. Le Guennic, O. Maury, O. Cador, G. Nocton, Inorg. Chem. 2019, 58, 2872-2880.

[17] F. Pointillart, O. Cador, B. Le Guennic, L. Ouahab, Coord. Chem. Rev. 2017, 346, 150175.

[18] aF. Jaroschik, F. Nief, L. Ricard, Chem. Commun. 2006, 426-428; bF. Jaroschik, A. Momin, A. Martinez, D. Harakat, L. Ricard, X. F. Le Goff, G. Nocton, Organometallics 2016, 35, 2032-2038.

[19] a) J. Rausch, C. Apostolidis, O. Walter, V. Lorenz, C. G. Hrib, L. Hilfert, M. Kühling, S. Busse, F. T. Edelmann, New J. Chem. 2015, 39, 7656-7666; b) G. W. Rabe, M. ZhangPresse, J. A. Golen, A. L. Rheingold, Acta Crystallogr. E 2003, 59, m1 102-m1103; c) S.D. Jiang, S.-S. Liu, L.-N. Zhou, B.-W. Wang, Z.-M. Wang, S. Gao, Inorg. Chem. 2012, 51, 3079-3087; d) H. Schumann, J. Winterfeld, H. Hemling, F. E. Hahn, P. Reich, K.-W. Brzezinka, F. T. Edelmann, U. Kilimann, M. Schäfer, R. Herbst-Irmer, Chem. Ber. 1995, 128, 395-404; e) Y.-S. Meng, Y.-S. Qiao, Y.-Q. Zhang, S.-D. Jiang, Z.-S. Meng, B.-W. Wang, Z.-M. Wang, S. Gao, Chem. Eur. J. 2016, 22, 4704-4708; f) V. Lorenz, P. Liebing, A. Bathelier, F. Engelhardt, L. Maron, L. Hilfert, S. Busse, F. T. Edelmann, Chem. Commun. 2018, 54, 10280-10283.

[20] R. Shannon, Acta Crystallogr. A 1976, 32, 751-767. 
[21] F. Jaroschik, F. Nief, X. F. Le Goff, L. Ricard, Organometallics 2007, 26, 3552-3558.

[22] aA. Jaoul, M. Tricoire, J. Moutet, M. Cordier, C. Clavaguéra, G. Nocton, Chem. Sq. 2019, 3, 1; bD. Wang, J. Moutet, M. Tricoire, M. Cordier, G. Nocton, Inorganics 2019, 7.

[23] aJ. Xia, Z. Jin, W. Chen, J. Chem. Soc., Chem. Commun. 1991, 1214-1215; bJ. J. Le Roy, L. Ungur, I. Korobkov, L. F. Chibotaru, M. Murugesu, J. Am. Chem. Soc. 2014, 136, 8003-8010.

[24] J. D. Rinehart, J. R. Long, Chem. Sci. 2011, 2, 2078-2085.

[25] a) S. T. Liddle, J. van Slageren, Chem. Soc. Rev. 2015, 44, 6655-6669; b) M. Gregson, N. F. Chilton, A.-M. Ariciu, F. Tuna, I. F. Crowe, W. Lewis, A. J. Blake, D.

Collison, E. J. L. McInnes, R. E. P. Winpenny, S. T. Liddle, Chem. Sci. 2016, 7, 155-165; c)

E. Rousset, M. Piccardo, M.-E. Boulon, R. W. Gable, A. Soncini, L. Sorace, C. Boskovic,

Chem. Eur. J. 2018, 24, 14768-14785. 